NBER WORKING PAPER SERIES

\title{
COVID-19 HAS STRENGTHENED THE RELATIONSHIP BETWEEN ALCOHOL CONSUMPTION AND DOMESTIC VIOLENCE
}

\author{
Aaron Chalfin \\ Shooshan Danagoulian \\ Monica Deza \\ Working Paper 28523 \\ http://www.nber.org/papers/w28523 \\ NATIONAL BUREAU OF ECONOMIC RESEARCH \\ 1050 Massachusetts Avenue \\ Cambridge, MA 02138 \\ March 2021
}

We thank Ross Epstein of SafeGraph for providing us with the data and helping us understand it. This research was supported by the Integrative Biosciences Center (IBio) which has received grant funding from the Michigan Health Endowment Foundation The views expressed herein are those of the authors and do not necessarily reflect the views of the National Bureau of Economic Research.

NBER working papers are circulated for discussion and comment purposes. They have not been peerreviewed or been subject to the review by the NBER Board of Directors that accompanies official NBER publications.

(C) 2021 by Aaron Chalfin, Shooshan Danagoulian, and Monica Deza. All rights reserved. Short sections of text, not to exceed two paragraphs, may be quoted without explicit permission provided that full credit, including (C) notice, is given to the source. 
COVID-19 Has Strengthened the Relationship Between Alcohol Consumption and Domestic

Violence

Aaron Chalfin, Shooshan Danagoulian, and Monica Deza

NBER Working Paper No. 28523

March 2021

JEL No. I1

\begin{abstract}
A large body of evidence documents a link between alcohol consumption and violence involving intimate partners and close family members. Recent scholarship suggests that since the onset of the COVID-19 pandemic and subsequent stay-at-home orders, there has been a marked increase in domestic violence. This research considers an important mechanism behind the increase in domestic violence during the COVID-19 pandemic: an increase in the riskiness of alcohol consumption. We combine 911 call data with newly-available high-resolution microdata on visits to bars and liquor stores in Detroit, MI and find that the strength of the relationship between visits to alcohol outlets and domestic violence more than doubles starting in March 2020. We find more limited evidence with respect to non-domestic assaults, supporting our conclusion that it is not alcohol consumption per se but alcohol consumption at home that is a principal driver of domestic violence
\end{abstract}

Aaron Chalfin

558 McNeil Building, 3718 Locust Walk

Department of Criminology

Philadelphia, Penn 19104

United States

achalfin@sas.upenn.edu

Shooshan Danagoulian

Department of Economics

Wayne State University

656 W. Kirby St.

FAB 2095

Detroit, MI 48202

fr4523@wayne.edu
Monica Deza

Department of Economics

Hunter College

City University of New York

New York, NY 10065

and NBER

monica.deza@hunter.cuny.edu 


\section{Introduction}

The statistics on domestic violence are grim: 1 in every 4 women in the United States will experience violence at the hands of an intimate partner during her lifetime (Alhabib et al., 2010). The consequences of domestic violence include not only the shorter-term physical injuries (Le et al., 2001; Plichta, 2004; Sheridan and Nash, 2007; Ellsberg et al., 2008) and mental harms (Roberts et al., 1998; Tolman and Rosen, 2001; Humphreys and Thiara, 2003) that are the immediate consequences of abuse, but also longer-term medical issues such as chronic pain (Wuest et al., 2008), depression (Dienemann et al., 2000), sexuallytransmitted diseases (Martin et al., 1999), and post-traumatic stress disorder (Jones et al., 2001). Given that approximately half of all domestic violence occurs in households where children under the age of 12 are present, domestic violence imposes a terrible burden, not only on the victim of the abuse, but also on children who witness it (Holt et al., 2008). Given the psychosocial malleability of children, domestic violence has profound implications for their cognitive and social development. Sadly, this burden compounds itself generation after generation, becoming an engine for the intergenerational transmission of violence (Simons et al., 1995).

The COVID-19 pandemic and its many accompanying disruptions to economic and social life have changed the world both unexpectedly and dramatically. In addition to mechanically increasing exposure to violence for those who are not safe at home (Peterman et al., 2019), stay-at-home-orders have affected a host of determinants of domestic violence such as increasing stress brought by job loss and material deprivation (Bitler et al., 2020),

gender equality (Alon et al., 2020), and mental health (Pfefferbaum and North, 2020) (Galea et al., 2020) among others. Stay-at-home-orders may also create hostile conditions at home, 
aggravate already hostile conditions, prevent victims from fleeing violent situations or filing protective orders, and reduce availability of police officers to respond to domestic arguments. Consistent with the expectations of many observers (Taub, 2020), recent scholarship has documented a notable increase in domestic violence since March 2020 in the US as well as in a number of other countries (Boserup et al., 2020; Leslie and Wilson, 2020a; McCrary and Sanga, 2020; Leslie and Wilson, 2020b). In this paper, we build upon this literature and provide novel evidence for an important mechanism through which lockdowns have affected household violence; we argue that during the COVID-19 pandemic, consumption of alcohol has become more risky, as the venue of consumption has shifted into homes, leading to increased intra-personal conflict.

The relationship between alcohol and violence is well documented. Alcohol use is implicated in approximately 50 percent of all violent crimes and sexual assaults in industrialized nations (Heinz et al., 2011) and a large literature in public health, criminology and economics establishes a correlational and, more recently, a causal link between problematic drinking and violence (Carpenter and Dobkin, 2009, 2011; Chalfin et al., 2019; Kypri et al., 2014). Research shows that both the perpetration of violence and victimization increases discretely at age 21 , the age at which individuals can legally drink alcohol in the United States (Chalfin et al., 2019; Kypri et al., 2014). There is likewise evidence that policy levers such as Sunday liquor laws, "wet laws" that expand the footprint of drinking establishments, underage driving laws, and alcohol excise taxes can have an important impact on public safety as well as morbidity and mortality rates. Owing to its effects on aggression and the ease with which it can change the nature of routine activities among members of the same household, alcohol consumption has been linked, in particular, to violence between family 
members, especially intimate partners (Bushman, 2002; Livingston, 2010; Markowitz and Grossman, 1998; Foran and O’Leary, 2008; Caetano et al., 2001).

By making it more difficult to drink in bars or restaurants, the COVID-19 pandemic has pushed alcohol consumption into residential settings (Usher et al., 2020). The majority of recent studies suggest that alcohol consumption has increased since March 2020 (Biddle et al., 2020; Brenmer, 2020), though there is no definitive empirical evidence of such a trend (Chodkiewicz et al., 2020). To the extent that residential and non-residential alcohol consumption are differentially conducive to violence — especially domestic violence the pandemic provides an unfortunate but unique opportunity to better understand the extent to which venue of alcohol consumption differentially affects violence. We test this hypothesis by merging public microdata on 911 calls for police service in Detroit, MI, with newly available-and remarkably detailed-geo-location data that allows us to measure daily visits to bars and liquor stores. We study whether Michigan's March 2020 stay-at-home order — which led to a dramatic reduction in drinking at bars and restaurants — changed the relationship between alcohol purchases and community violence. Consistent with prior research, during the pre-pandemic period, we observe a positive relationship between visits to both bars and liquor stores and general violence. After the onset of the COVID-19 pandemic and the subsequent stay-at-home order issued by Michigan Governor Gretchen Whitmer, there is evidence that the relationship between alcohol consumption and violence — especially domestic violence — strengthens considerably. This effect is especially large for visits to liquor stores which account for the majority of alcohol purchases in the postpandemic period and is even stronger when we flexibly account for temporal spillovers from alcohol purchases. We find considerably more limited evidence for a change in the 
relationship between alcohol purchases and non-domestic assaults, which is consistent with the idea that alcohol consumption at home has a particularly close nexus to domestic violence.

The remainder of the paper is organized as follows. In Section 2 we present our data and empirical models. Section 3 presents our findings and Section 4 concludes.

\section{Data and Methods}

\subsection{Data}

\subsubsection{Customer Visit Data}

We measure the number of visits to establishments that sell alcohol using data from SafeGraph's Patterns platform, which organizes location data for commercial points of interest (POIs). The SafeGraph data consists of high-resolution cellular device location data that link tracked mobile devices to specific commercial establishments in space and time. The data combine information on more than 4 million POIs in the US with visit patterns collected by SafeGraph using location tracking apps. The data contain information on POI location name, address, North American Industry Classification System (NAICS) code, brand association, and business descriptor categories as well as the volume of daily visits to each establishment. We restrict the data to visits to POIs within Detroit determined by zip code. Using NAICS codes, we further restrict the data to POI visits associated with sale or service of alcohol. These include grocery stores (NAICS 445110, 445120, 445210, 445220, 445230, 44591, 445292 $)^{1}$; bars and restaurants with an explicit focus on alcoholic beverages

\footnotetext{
${ }^{1}$ Full-line grocery stores in Michigan may be licensed to sell all alcohol. Our definition of grocery extends beyond full-line grocery stores, including specialty stores that may carry alcohol as well.
} 
(NAICS 722410, 722511) ; full service restaurants excluding bars (NAICS 722511); and beer, wine, and liquor stores (NAICS 445310, henceforth liquor stores). We aggregate the daily number of visits by type of establishment within each zip code. The choice of geographic unit is constrained by the 911 calls data, discussed below; the choice of time unit is conditioned by our desire to use highly granular time fixed effects to remove variation due to confounding factors which are more likely to co-move within a week. While SafeGraph data does provide the census block group of visitors to the alcohol outlets, we are unable to use this information as it is available only aggregated to the week.

While the SafeGraph data allow us to identify foot traffic to alcohol outlets with remarkable granularity, they are subject to three important limitations. First, we are unable to track every cellular phone in the United States. While this could potentially lead to selection bias, we note that SafeGraph's internal research has found that the sample of users is representative of the US population at the census block group level. ${ }^{3}$ Second, these data do not constitute a comprehensive count of visits to a particular POI, as they are not based on the universe of cellular devices, nor do they capture visits by individuals without cellular devices. To address this limitation, our analysis focuses on changes in the volume of visits, rather than the number of visits. Finally, visits to alcohol outlets do not allow us to observe the amount of alcohol purchased or when it was consumed. While this is a notable limitation, our estimates — which relate violence to the number of visits to alcohol outlets - nevertheless constitute prima facie evidence that violence is sensitive to the timing and location of alcohol purchases. We further note that if there is imperfect corre-

\footnotetext{
${ }^{2}$ Because NAICS 722410 only includes establishments that serve alcohol but no food, we extended the definition of bars to include full-line restaurants with the following terms in their business descriptor categories: "Bar or Pub", "Cocktail", "Sports Bar", "Dive Bar", "Brewery".

${ }^{3}$ More detail on SafeGraph analysis can be found at: https://www.safegraph.com/blog/what-about-bias-in-the-safegraph-dataset.
} 
spondence between the visit data and alcohol consumption, and as long as the errors are uncorrelated with community violence, this generates a conservative bias in our "reduced form" estimates.

\subsubsection{Call Data}

We measure violence known to law enforcement using 911 call data from the City of Detroit Open Data Portal. The 911 calls for service dataset compiles all emergency calls requiring law enforcement response as well as officer-initiated calls for service in the City of Detroit. Between January 1, 2019 and June 10, 2020 there were 1,471,211 calls for emergency service. The dataset includes two types of calls: (1) emergency response calls, which result from people requesting police services by calling 911 directly, and (2) officer-initiated calls, which document policing activities such as traffic stops, street investigations, and other situations where a police officer initiates the response. For each call, we observe the responding agency, zip code of incident, information about the agency (precinct, responding unit), date of incident, information about response to the incident (time on scene, total response time, total time, travel time, intake time), and information regarding the nature of the call (call code number, call description). We use a combination of call code numbers and call descriptions to identify which assault calls can be attributed to domestic violence and which cannot. We define non-domestic assault as either felonious assault ${ }^{4}$ or assault and battery ${ }^{5}$. We define domestic violence as calls concerning inter-partner and intra-household violence, including child or adult abuse with or without a weapon, with or without a report. ${ }^{6}$ We sum domestic violence calls and assaults to the uniquely identified zip code, year, month, and

\footnotetext{
${ }^{4}$ Call code numbers 343010, 343020, 343040

${ }^{5}$ Call code numbers 347010, 347020, 347021, 347040

${ }^{6}$ Call code numbers 393010, 393030, 395010, 395030, 396010, 396030, 397010, 397030.
} 
day. Our analysis is based on 26 zip codes tracked across 552 days, totalling 14,352 zip code observations per day between January 1, 2019 and July 4, 2020.

\subsubsection{Descriptive Analysis}

Figure 1 presents unadjusted trends in domestic assault (Panel A) and non-domestic assault (Panel B) along with the liquor store share of visits to outlets that sell alcohol. Both panels provide evidence of substantial seasonal variation in violence, with both domestic and non-domestic assaults peaking in the summer months and reaching their lowest points between November and March. While non-domestic assaults increased in summer 2020 to levels comparable to those in summer 2019, domestic assaults are noticeably higher in summer 2020. In accordance with emerging literature on this topic (Boserup et al., 2020; Leslie and Wilson, 2020a), the figure thus provides suggestive evidence that, unlike general forms of violence, domestic violence has increased during the pandemic, even after taking seasonal trends into account.

The figure also suggests that the sources of alcohol consumption have changed markedly. Prior to the onset of the pandemic the relative share of visits to liquor stores was remarkably stable, at approximately $30 \%$. As stay-at-home orders closed bars and restaurants, liquor stores became the main venue of alcohol sales. By May 2020, liquor stores accounted for over $70 \%$ of all visits to alcohol outlets. Taken together, the two series suggest that domestic violence might be particularly sensitive to venue of alcohol consumption.

Next, in Table 1, we present summary statistics for our zip-code-by-date-level analytic dataset. We report descriptive statistics for the entire city (Panel A) as well as for zip codes with a higher than median number of 911 calls for violence (Panel B) and a lower than median number of 911 calls for violence (Panel C). With respect to pre-pandemic visits, we 
observe 235 daily visits to restaurants, 99 daily visits to food stores, 90 daily visits to bars, and 35 daily visits to liquor stores in an average zip code. As the SafeGraph data allow us to observe only a fraction of all visits, these numbers do not have a direct interpretation. However, ratios and trends are highly instructive. In the pre-pandemic period, there were 2.5 visits to bars for every visit to a liquor store. Since the onset of the pandemic, the ratios have reversed. In the post-March 2020 period, there has been a notable decline in the number of visits to alcohol outlets. However, while visits to bars have declined by more than 80 percent, visits to liquor stores have declined by around one third. These declines are consistent with an overall decline in consumer activity, as evidenced from large declines in the number of customer visits to restaurants and food outlets. In subsequent analyses, we control for visits to restaurants and food outlets in order to account for the large secular decline in economic activity that has been brought about by the pandemic.

\subsection{Empirical Methods}

We study the effect of community-level alcohol sales on violence using natural variation in the measured number of visits to alcohol outlets. We focus, in particular, on two types of alcohol outlets: bars and liquor stores and two types of violence: domestic violence and no-domestic assaults. In order to estimate the proportional change in violence with respect to visits to alcohol outlets, we estimate Poisson regression models in which the count of 911 calls made in a zip code on a date is $Y_{i t} .{ }^{7}$ In (1), $Y_{i t} \sim \operatorname{Poisson}\left(\gamma_{i t}\right)$, is regressed on the number of measured visits to each type of alcohol establishment. In order to account for changing behavior introduced by stay-at-home orders, we interact the number of measured visits for each type of alcohol establishment with an indicator for the post-March 10 period.

\footnotetext{
${ }^{7}$ As a robustness check, we also estimate models via ordinary least squares.
} 
We define the post-COVID period flexibly, dividing it into a March 10-May 25 period, when the stay-at-home was in effect, and a May 26-June 10 period, when the order was lifted. In practice, our empirical estimates focus on the stay-at-home period.

$$
\begin{array}{r}
\log \left(\gamma_{i t}\right)=\alpha+\sum_{j=1}^{4} \xi^{j}\left[\ln (\text { VISITS })_{i t}^{j}\right]+ \\
+\sum_{j=1}^{4} \beta^{j}\left[\ln (\text { VISITS })_{i t}^{j} \times P O S T_{i t}\right]+ \\
+\rho X_{i t-1}+\lambda_{i}+\delta_{t}
\end{array}
$$

In (1), VISIT $S_{i t}^{j}$ is the daily number of measured visits in a given zip code to an establishment of type $j$. We include all establishments which serve alcohol - bars, liquor stores, restaurants, and grocery stores. Though restaurants and grocery stores are not primarily sources of alcohol sales, we include them for completeness. The post March 2020 period is identified using $P O S T_{i} t$ indicator and interacted with the visit terms separated by alcohol outlet type. In practice, we separate the pandemic into two post-periods, $P O S T 1_{i t}$ and $P O S T 2_{i t}$, which are equal to one for the time periods between March 10-May 25 and May 26-July 5, 2020, respectively, and zero for pre-pandemic time periods. Accordingly, $e^{\xi^{j}}$ are the incidence rate ratios for the pre-pandemic period and $e^{\beta^{j}}$ are the incidence rate ratios for the stay-at-home period. These coefficients provide an estimate of the elasticity of violence with respect to visits to each type of establishment. In auxiliary models, we allow for temporal spillovers in the effect of alcohol consumption by including various lags for each of the visit variables.

In all models, we condition on $X_{i t-1}$, the number of shootings in a given zip code in the previous day, a proxy for stress which may be induced by serious violence experienced 
recently. We include zip code fixed effects, $\lambda_{i}$, in order to absorb time-invariant characteristics across zip codes in Detroit and day-by-month fixed effects and year fixed effects, $\delta_{t}$, which account for daily variation in citywide crime trends. In practice, we utilize an additional innovation, allowing $\delta_{t}$ to vary according to whether a zip code's baseline number of 911 calls for violence is above or below the median. This innovation is notable in that it allows us to account for events, whether observable or not, which vary over time and and have differing effects on relatively poor and relatively affluent communities. For example, though the post-pandemic period coincides with the a number of protests associated with police killings of Black civilians, to the extent that such events have similar effects across similar neighborhoods, they are accounted for by the interacted fixed effects. In all models, standard errors are clustered at the zip code level to account for both heteroskedasticity and arbitrary serial correlation in the error terms for observations in the same geographic unit measured at different time periods (Bertrand et al., 2004).

While the data allow us to identify foot traffic to alcohol outlets with remarkable granularity, the data do have several limitations. First, as not every cellular phone in the United States is tracked with these data, our measure of visits is imperfect. To the extent that there are systematic errors in the data, this could lead to bias in our estimates. That said, we note that as long as errors in the data are unrelated to violence - and we have no reasons to suspect that they are - this will bias our estimates downward (Hyslop and Imbens, 2001; Chalfin and McCrary, 2018). As such, our estimates may, if anything, be conservative. Second, while we argue that visits to alcohol outlets are a reasonable proxy for the volume of alcohol consumed, we are unable to measure the amount of alcohol purchased or when it was consumed. Since liquor purchased at liquor stores can be consumed for a long period 
of time after purchase, our proxy for alcohol consumption is imperfect. In order to address this issue, we test for lagged effects of visits to alcohol outlets and find some evidence of delayed effects.

Before presenting results, one more feature of the data requires discussion. The visit data we use cover only a subset of cellular devices in the city of Detroit; consequently $\operatorname{VISIT} S_{i t}^{j}$ is measured with error. For any given establishment, these errors may be large, so we aggregate the data up to the zip code to shrink the degree of any resulting bias. Nevertheless, it is worth considering the extent to which our estimate of $\beta^{j}$ might be subject to measurement error bias. We begin by noting that measurement errors that are persistent across space and time - for example, if data errors are more common in zip codes or on days where traffic to alcohol outlets is high — will be addressed by the fixed effects. That is, zip-code and time-invariant measurement errors will not lead to bias in our estimates. On the other hand, consider the possibility that the measurement errors are random. In this case, the classical measurement error model will hold and our estimate of $\beta^{j}$ will be attenuated toward zero; as such our estimates would be conservative (Wooldridge, 2002; Cameron and Trivedi, 2005). ${ }^{8}$ Since we do not have a second measure of visits, we cannot formally derive the magnitude of any attenuation that is present in the models. However, given the relatively small degree of within-zip code heterogeneity in the visits data, the scope for measurement error bias to be an important source of error in our estimates is reduced.

\footnotetext{
${ }^{8}$ For two prominent applications of the classical measurement model to the economics of crime literature, see Chalfin and McCrary (2018) for an application to police and Donohue III and Levitt (2008) for an application to abortion rates.
} 


\section{Results}

Our principal estimates are presented in Table 2. We report estimates from equation (1) for the entirety of Detroit (Panel A) as well as for zip codes with higher than median 911 call volumes (Panel B) and lower than median 911 call volumes (Panel C). In each panel, we present estimates separately for domestic and non-domestic assaults. We likewise present estimates separately for both the pre-pandemic period (the $\xi^{j}$ terms in equation 1) and the first part of the post-pandemic period (the $\beta^{j}$ terms in equation 1 ) for each of the four types of establishment: bars, liquor stores, restaurants, and food outlets.

With respect to domestic assaults, there is little evidence that domestic violence is related to either bar or liquor store visits prior to the COVID-19 pandemic. However, we observe that domestic violence calls rise with the number of visits to both bars and liquor stores in the post-pandemic period. In particular, the elasticity of domestic violence calls with respect to visits increases by approximately 0.049 for bars and 0.063 for liquor stores. While these level changes are modest, we note that they are reduced forms and do not ac-

count for temporal spillovers in alcohol consumption. The sub-city analysis indicates that the relationship between liquor store visits and domestic violence is particularly strong in low-crime zip codes, while the relationship between bar visits and domestic violence is particularly strong in high-crime zip codes. In contrast to domestic assaults, the relationship between visits to alcohol outlets and non-domestic assaults does not strengthen significantly in the post-pandemic period. As such, even though alcohol consumption may interact positively with pandemic-induced stress, this has not led to an increase in alcohol-induced violence more generally.

While we condition on a granular set of fixed effects, concerns about omitted variable 
bias may remain. In order to test for the possibility that the effects we observe are part and parcel of broader trends in economic activity and the movement of people in a community, we consider whether domestic violence is impacted by visits to restaurants and food stores. As expected, we find little evidence of a positive relationship between restaurants or food outlets and violence, whether residential or non residential, pre- or post-pandemic.

Because alcohol purchased at a liquor store can be consumed for a period of time after its purchase, we next consider the lagged effect of visits to alcohol outlets. We run an auxiliary model in which we augment equation (1) to include the first and second lags of visits to each type of commercial outlet in each time period studied. These terms allow us to observe dynamic correlations between violence and alcohol purchases made in the prior two days. We present these results in Table 3. In the table, we present the cumulative effect of three consecutive days of visits by summing coefficients on concurrent and two lagged effects. The cumulative coefficients are presented for bars and liquor stores only. For bars, the estimates presented in Table 3 are twice as large as those in Table 2, offering evidence in favor of temporal spillovers. On the other hand, for liquor stores, the estimates in Table 3 are approximately $50 \%$ larger than those in Table 2, indicating that the elasticities reported in Table 2 are conservative estimates of the effect of alcohol consumption on domestic violence.

\section{Discussion}

In this research, we show that the relationship between visits to alcohol outlets and domestic violence - but not other forms of violence - has grown considerably stronger since March 2020. Our conclusions are based on newly-available data provided by SafeGraph that allow us to estimate daily changes to the number of visitors to establishments selling alcohol. Due 
to the remarkable resolution of the data, we are able to construct a daily proxy for alcohol consumption in each community, a measure that researchers have long wished to use but which has, until recently, been impossible to collect due to technological limitations.

Why has alcohol consumption become riskier during the pandemic? We offer three reasons. First, the location of alcohol consumption changed markedly since stay-at-home orders took effect. Whereas liquor stores accounted for only 28 percent of visits to alcohol outlets in the pre-pandemic period, since March 2020 this proportion has more than doubled to nearly 60 percent. Second, the COVID-19 pandemic has led to job loss, economic hardship, and a great deal of stress as families struggle to cope with considerable disruptions to their daily lives. While it is easy to imagine that these factors have led to an increase in violence in the absence of alcohol, it also stands to reason that they have made alcohol consumption riskier. Finally, stay-at-home orders have mechanically increased the amount of time that people are spending at home (Peterman et al., 2019). As such, the opportunity for problematic drinking to lead to family violence has increased. At the same time, we observe little evidence that the relationship between alcohol and other types of violence has changed since the COVID-19 pandemic. As such it appears as though the pandemic has caused a substitution of violence away from acquaintances and strangers and toward family members.

Beyond developing a deeper understanding of the effects of the COVID-19 pandemic, this research contributes to the large literature that studies geo-spatial correlations between the location of alcohol outlets and violence (Gruenewald et al., 2006; Franklin et al., 2010; Grubesic and Pridemore, 2011; Roman and Reid, 2012). By leveraging highly granular visit data and exploiting changes in the density of visits over time, we are able to draw stronger 
causal inferences about the relationship between alcohol outlets and community violence. Our estimates suggest that regardless of the COVID-19 pandemic, visits to bars and liquor stores lead to increased violence, providing more credible evidence that prior evidence is not merely correlational.

This research likewise helps to deepen our understanding of the nature of domestic violence, suggesting that the venue of alcohol consumption, rather than merely the volume of alcohol consumed may be a principal driver of household violence. The idea that venue may be an important characteristic of alcohol consumption can be found in research on the minimum legal drinking age (Chalfin et al., 2019) and is likewise implicated in research that suggests that family violence is triggered by frustration such as that which is generated by an unexpected football loss (Card and Dahl, 2011). However, thus far, this has been mostly a topic of speculation and has been subject to little empirical testing. Our principle finding - that the relationship between alcohol purchases and domestic violence but not other forms of violence - has grown considerably stronger since the pandemic, is among the most direct evidence, to date, that venue matters. 


\section{References}

Alhabib, S., U. Nur, and R. Jones (2010). Domestic violence against women: Systematic review of prevalence studies. Journal of Family Violence 25(4), 369-382.

Alon, T., M. Doepke, J. Olmstead-Rumsey, and M. Tertilt (2020). The impact of covid-19 on gender equality. National Bureau of Economic Research WP26947.

Bertrand, M., E. Duflo, and S. Mullainathan (2004). How much should we trust differencesin-differences estimates? The Quarterly Journal of Economics 119(1), 249-275.

Biddle, N., B. Edwards, M. Gray, and K. Sollis (2020). Alcohol consumption during the covid-19 period: May 2020. COVID-19 Briefing Paper.

Bitler, M., H. Hoynes, and D. W. Schanzenbach (2020). The social safety net in the wake of covid-19. National Bureau of Economic Research WP27r96.

Boserup, B., M. McKenney, and A. Elkbuli (2020). Alarming trends in us domestic violence during the covid-19 pandemic. The American Journal of Emergency Medicine.

Brenmer, J. (2020). Alcohol sales increase 55 percent in one week amid coronavirus pandemic.

Bushman, B. J. (2002). Effects of alcohol on human aggression. In Recent Developments in Alcoholism, pp. 227-243. Springer.

Caetano, R., J. Schafer, and C. B. Cunradi (2001). Alcohol-related intimate partner violence among white, black, and hispanic couples in the united states. Alcohol Research $\&$ Health 25(1), 58.

Cameron, A. C. and P. K. Trivedi (2005). Microeconometrics: methods and applications. Cambridge university press.

Card, D. and G. B. Dahl (2011). Family violence and football: The effect of unexpected emotional cues on violent behavior. The Quarterly Journal of Economics 126(1), 103143.

Carpenter, C. and C. Dobkin (2009). The effect of alcohol consumption on mortality: regression discontinuity evidence from the minimum drinking age. American Economic Journal: Applied Economics 1(1), 164-82.

Carpenter, C. and C. Dobkin (2011). The minimum legal drinking age and public health. Journal of Economic Perspectives 25(2), 133-56.

Chalfin, A., B. Hansen, and R. Ryley (2019). The minimum legal drinking age and crime victimization. Technical report, National Bureau of Economic Research.

Chalfin, A. and J. McCrary (2018). Are us cities underpoliced? theory and evidence. The Review of Economics and Statistics 100(1), 167-186.

Chodkiewicz, J., M. Talarowska, J. Miniszewska, N. Nawrocka, and P. Bilinski (2020). Alcohol consumption reported during the covid-19 pandemic: The initial stage. International Journal of Environmental Research and Public Health 17(13), 4677. 
Dienemann, J., E. Boyle, D. Baker, W. Resnick, N. Wiederhorn, and J. Campbell (2000). Intimate partner abuse among women diagnosed with depression. Issues in Mental Health Nursing 21(5), 499-513.

Donohue III, J. J. and S. D. Levitt (2008). Measurement error, legalized abortion, and the decline in crime: A response to foote and goetz. The Quarterly Journal of Economics 123(1), 425-440.

Ellsberg, M., H. A. Jansen, L. Heise, C. H. Watts, C. Garcia-Moreno, et al. (2008). Intimate partner violence and women's physical and mental health in the who multi-country study on women's health and domestic violence: an observational study. The Lancet 371 (9619), $1165-1172$.

Foran, H. M. and K. D. O'Leary (2008). Alcohol and intimate partner violence: A metaanalytic review. Clinical Psychology Review 28(7), 1222-1234.

Franklin, F. A., T. A. L. II, D. W. Webster, and W. K. Pan (2010). Alcohol outlets and violent crime in washington dc. Western Journal of Emergency Medicine 11(3), 283.

Galea, S., R. Merchant, and N. Lurie (2020). The mental health consequences of covid-19 and physical distancing: The need for prevention and early intervention. JAMA Internal Medicine 180(6), 817-818.

Grubesic, T. and W. Pridemore (2011). Alcohol outlets and clusters of violence. International Journal of Health Geographics $10(30)$.

Gruenewald, P. J., B. Freisthler, L. Remer, E. A. LaScala, and A. Treno (2006). Ecological models of alcohol outlets and violent assaults: crime potentials and geospatial analysis. Addiction 101(5), 666-677.

Heinz, A. J., A. Beck, A. Meyer-Lindenberg, P. Sterzer, and A. Heinz (2011). Cognitive and neurobiological mechanisms of alcohol-related aggression. Nature Reviews Neuroscience 12(7), 400-413.

Holt, S., H. Buckley, and S. Whelan (2008). The impact of exposure to domestic violence on children and young people: A review of the literature. Child abuse 83 Neglect 32(8), 797-810.

Humphreys, C. and R. Thiara (2003). Mental health and domestic violence:'i call it symptoms of abuse'. The British Journal of Social Work 33(2), 209-226.

Hyslop, D. R. and G. W. Imbens (2001). Bias from classical and other forms of measurement error. Journal of Business \& Economic Statistics 19(4), 475-481.

Jones, L., M. Hughes, and U. Unterstaller (2001). Post-traumatic stress disorder (ptsd) in victims of domestic violence: A review of the research. Trauma, Violence, $\&$ Abuse 2(2), 99-119.

Kypri, K., G. Davie, P. McElduff, J. Connor, and J. Langley (2014). Effects of lowering the minimum alcohol purchasing age on weekend assaults resulting in hospitalization in new zealand. American Journal of Public Health 104(8), 1396-1401. 
Le, B. T., E. J. Dierks, B. A. Ueeck, L. D. Homer, and B. F. Potter (2001). Maxillofacial injuries associated with domestic violence. Journal of Oral and Maxillofacial Surgery 59(11), 1277-1283.

Leslie, E. and R. Wilson (2020a). Sheltering in place and domestic violence: Evidence from calls for service during covid-19. Available at SSRN 3600646.

Leslie, E. and R. Wilson (2020b). Sheltering in place and domestic violence: Evidence from calls for service during covid-19. Journal of Public Economics 189.

Livingston, M. (2010). The ecology of domestic violence: the role of alcohol outlet density. Geospatial Health 5(1), 139-149.

Markowitz, S. and M. Grossman (1998). Alcohol regulation and domestic violence towards children. Contemporary Economic Policy 16(3), 309-320.

Martin, S. L., L. S. Matza, L. L. Kupper, J. C. Thomas, M. Daly, and S. Cloutier (1999). Domestic violence and sexually transmitted diseases: the experience of prenatal care patients. Public Health Reports 114(3), 262.

McCrary, J. and S. Sanga (2020). The impact of coronavirus lockdown on domestic violence. SSRN Scholarly Paper ID 3612491 Rochester NY: Social Science Research Network.

Peterman, A., A. Potts, M. O'Donnell, K. Thompson, N. Shah, S. Oertelt-Prigione, and N. van Gelder (2019). Pandemics and violence against women and children. Center for Global Development Working Paper(528).

Pfefferbaum, B. and C. North (2020). Mental health and the covid-19 pandemic. New England Journal of Medicine.

Plichta, S. B. (2004). Intimate partner violence and physical health consequences: Policy and practice implications. Journal of Interpersonal Violence 19(11), 1296-1323.

Roberts, G. L., J. M. Lawrence, G. M. Williams, and B. Raphael (1998). The impact of domestic violence on women's mental health. Australian and New Zealand Journal of Public Health 22(7), 796-801.

Roman, C. G. and S. E. Reid (2012). Assessing the relationship between alcohol outlets and domestic violence: routine activities and the neighborhood environment. Violence and Victims 27(5), 811-828.

Sheridan, D. J. and K. R. Nash (2007). Acute injury patterns of intimate partner violence victims. Trauma, Violence, \& Abuse 8(3), 281-289.

Simons, R. L., C.-i. Wu, C. Johnson, and R. D. Conger (1995). A test of various perspectives on the intergenerational transmission of domestic violence. Criminology 33(1), 141-172.

Taub, A. (2020). A new covid-19 crisis: Domestic abuse rises worldwide. The New York Times.

Tolman, R. M. and D. Rosen (2001). Domestic violence in the lives of women receiving welfare: Mental health, substance dependence, and economic well-being. Violence against Women 7(2), 141-158. 
Usher, K., N. Bhullar, J. Durkin, N. Gyamfi, and D. Jackson (2020). Family violence and covid-19: Increased vulnerability and reduced options for support. International Journal of Mental Health Nursing.

Wooldridge, J. M. (2002). Econometric analysis of cross section and panel data mit press. Cambridge, MA 108.

Wuest, J., M. Merritt-Gray, M. Ford-Gilboe, B. Lent, C. Varcoe, and J. C. Campbell (2008). Chronic pain in women survivors of intimate partner violence. The Journal of Pain 9(11), 1049-1057. 


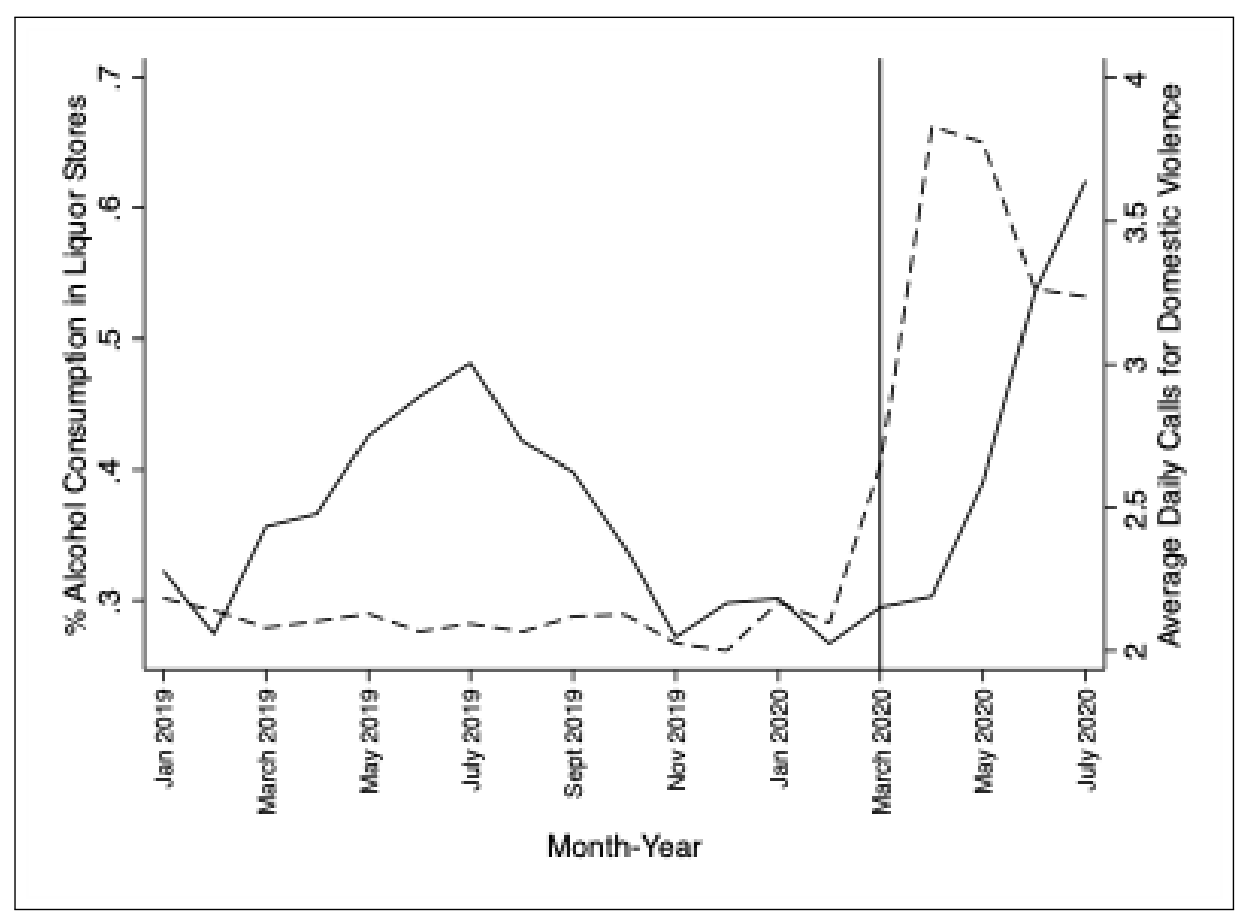

(a) Domestic Violence

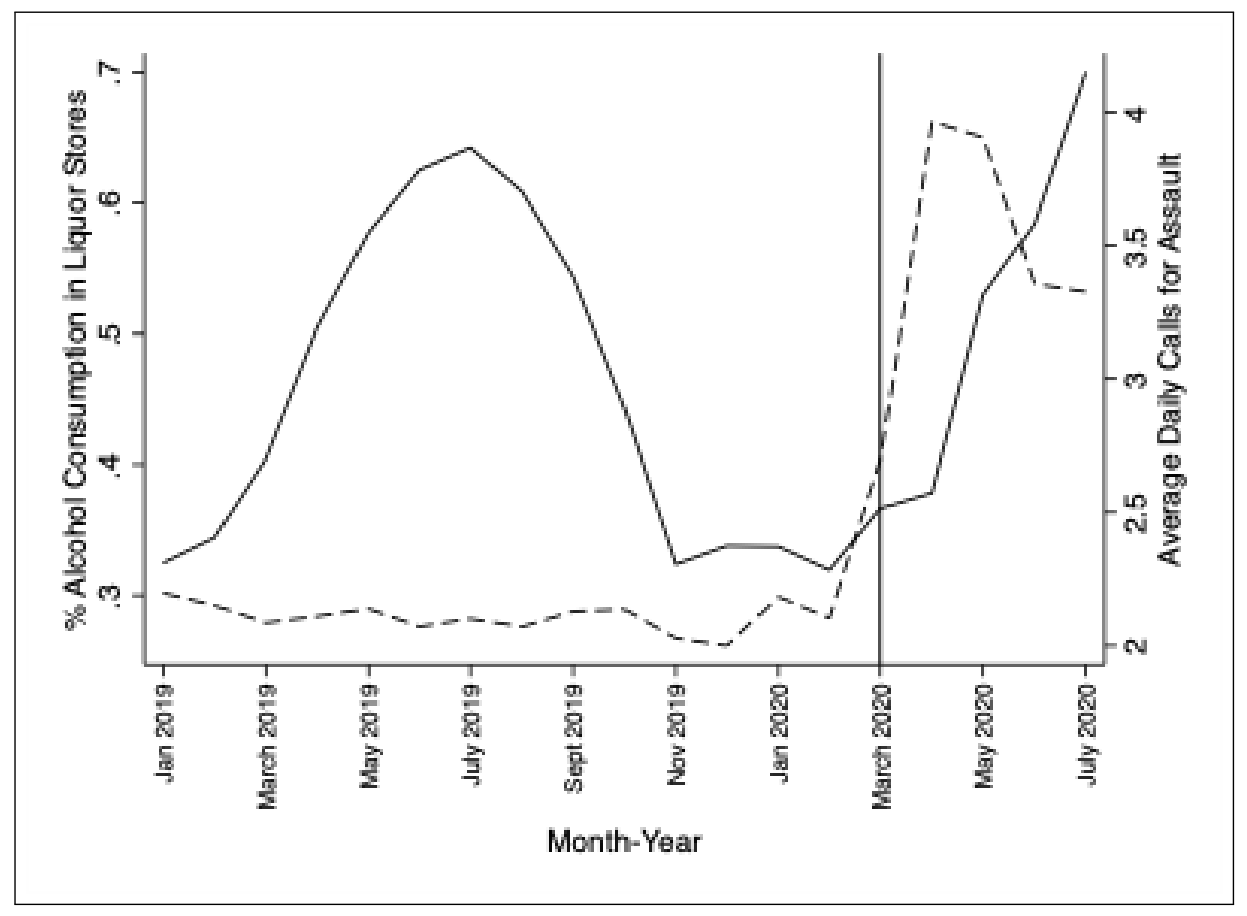

(b) Assault

Figure 1: Liquor store share of visits to alcohol outlets and violence

Note: Figure plots the time-path of the liquor store share of visits to alcohol outlets (the dotted lines) against the daily number of emergency calls for domestic assaults (Panel a) and other assaults (Panel b). Source: SafeGraph Patterns Data, 2018-2020. City of Detroit Open Data Portal 911 Calls for Service, 2018-2020. 23,166 observations of 26 zip codes. 
Table 1: Summary Statistics

Pre-Pandemic Post-Pandemic

Mean St. Dev. Mean St. Dev. Diff.

\section{A. Entire City}

\begin{tabular}{lccccc}
\hline & & & & \\
Bars & 89.63 & $(244.66)$ & 17.49 & $(44.95)$ & $-72.140^{* * *}$ \\
Liquor Stores & 35.46 & $(28.10)$ & 23.81 & $(19.77)$ & $-11.64^{* * *}$ \\
Restaurants & 235.05 & $(329.71)$ & 97.52 & $(106.48)$ & $-137.52^{* * *}$ \\
Food Outlets & 99.41 & $(208.52)$ & 58.90 & $(59.83)$ & $-40.51^{* * *}$ \\
\multicolumn{5}{c}{ B. High-Crime Zip Codes } \\
\hline \\
Bars & 23.01 & $(29.10)$ & 9.33 & $(13.06)$ & $-13.67^{* * *}$ \\
Liquor Stores & 49.82 & $(22.26)$ & 37.58 & $(17.65)$ & $-12.24^{* * *}$ \\
Restaurants & 170.49 & $(199.69)$ & 110.29 & $(117.64)$ & $-60.19^{* * *}$ \\
Food Outlets & 113.35 & $(277.19)$ & 72.23 & $(56.22)$ & $-41.11^{* * *}$
\end{tabular}

\section{A. Low-Crime Zip Codes}

\begin{tabular}{lccccc}
\hline & & & & & \\
Bars & 156.25 & $(331.66)$ & 25.65 & $(61.14)$ & $-130.61^{* * *}$ \\
Liquor Stores & 21.11 & $(25.91)$ & 10.05 & $(9.58)$ & $-11.05^{* * *}$ \\
Restaurants & 299.61 & $(411.36)$ & 84.75 & $(92.29)$ & $-214.85^{* * *}$ \\
Food Outlets & 85.47 & $(98.72)$ & 45.56 & $(60.37)$ & $-39.91^{* * *}$ \\
\hline
\end{tabular}

Source: SafeGraph Patterns Data, 2019-2020. City of Detroit Open Data Portal 911 Calls for Service, 2019-2020. 14,256 observations of 26 zip codes.

Significance: ${ }^{*} p<0.1,{ }^{* *} p<0.05,{ }^{* * *} p<0.01$. 


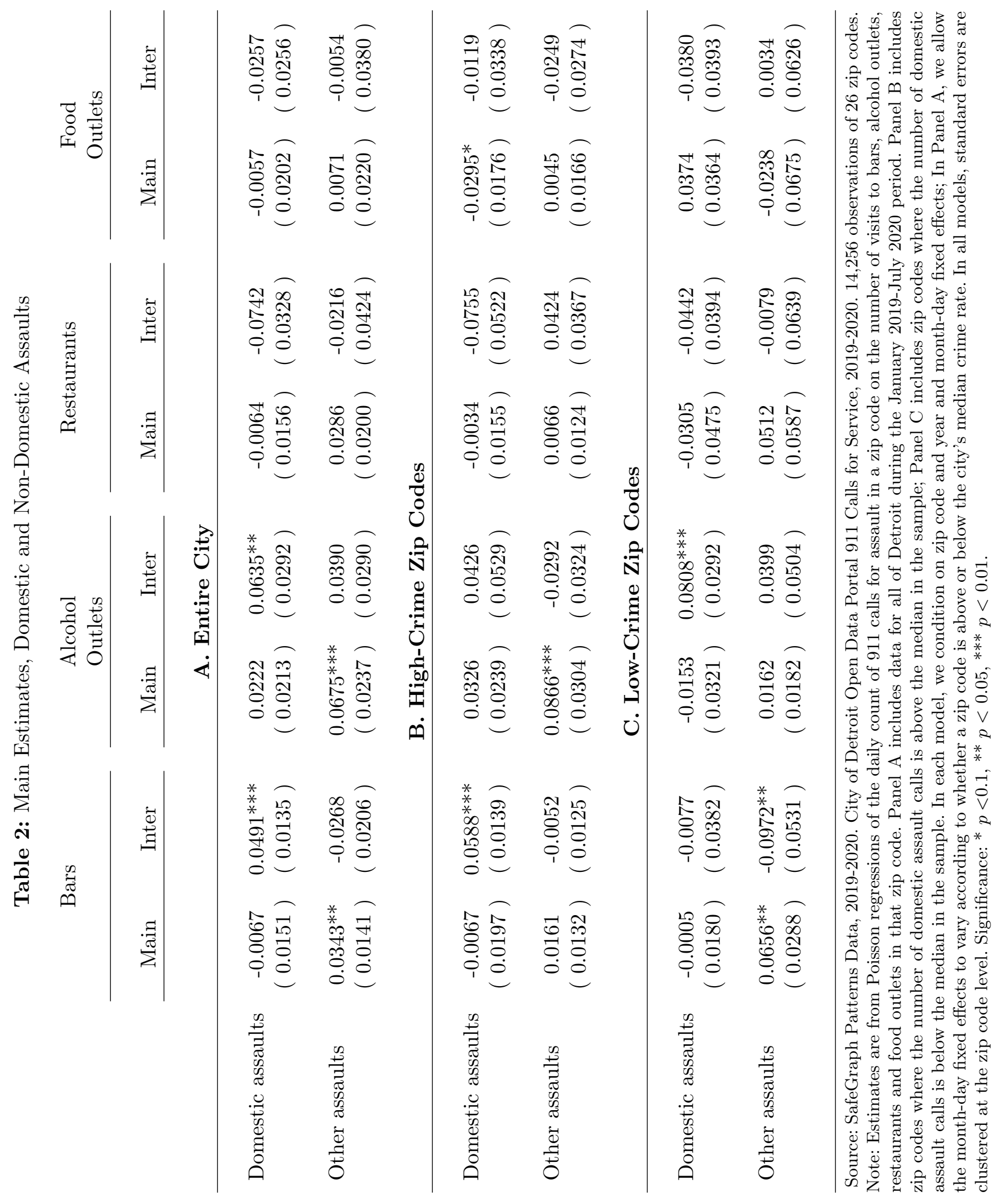


Table 3: Main Estimates, Domestic and Non-Domestic Assaults with Lagged Visits

Bars Alcohol

Outlets

$\begin{array}{cc}\beta_{j}+\beta_{L j}+\beta_{L 2 j} & \beta_{j}+\beta_{L j}+\beta_{L 2 j} \\ \text { (se) } & \text { (se) } \\ \mathrm{p} \text {-value } & \mathrm{p} \text {-value }\end{array}$

A. Entire City

Domestic Assaults

$0.1022^{* * *}$

$0.0948^{*}$

$(0.0304)$

$(0.0573)$

0.001

0.0980

Non-Domestic Assaults

0.0121

0.0498

$(0.0256)$

$(0.0453)$

0.635

0.271

\section{B. High-Crime Zip Codes}

$\begin{array}{lcc}\text { Domestic Assaults } & 0.1211^{* * *} & 0.0789 \\ & (0.0378) & (0.0941) \\ \text { Non-Domestic Assaults } & 0.001 & 0.402 \\ & 0.0368^{* *} & -0.0142 \\ & (0.0162) & (0.0325) \\ & 0.024 & 0.664\end{array}$

\section{Low-Crime Zip Codes}

$\begin{array}{lcc}\text { Domestic Assaults } & 0.0069 & 0.108 \\ & (0.0669) & (0.0799) \\ \text { Non-Domestic Assaults } & 0.917 & 0.176 \\ & -0.0442 & 0.0802 \\ & (0.0758) & (0.1036) \\ & 0.56 & 0.439\end{array}$

Source: SafeGraph Patterns Data, 2019-2020. City of Detroit Open Data Portal 911 Calls for Service, 20192020. 14,206 observations of 26 zip codes. Note: Estimates are from Poisson regressions of the daily count of 911 calls for assault in a zip code on the number of visits to bars, alcohol outlets, restaurants and food outlets in that zip code. Each model includes daily visits, visits interacted with indicator for March 10 - May 25 period, visits interacted with indicator for May 25 onward period; one day lag for visits and post-interacted visits to bars and alcohol outlets; and two day lag for visits and post-interacted visits to bars and alcohol outlets. Reported are the sum of coefficients for the March 10 - May 25 period for contemporaneous, one day lag, and two day lag effects. Panel A includes data for all of Detroit during the January 2019-July 2020 period. Panel B includes zip codes where the number of domestic assault calls is above the median in the sample; Panel $\mathrm{C}$ includes zip codes where the number of domestic assault calls is below the median in the sample. In each model, we condition on zip code and year and month-day fixed effects; In Panel A, we allow the month-day fixed effects to vary according to whether a zip code is above or below the city's median crime rate. In all models, standard errors are clustered at the zip code level. Significance: ${ }^{*} p<0.1,{ }^{* *} p<0.05,{ }^{* * *} p<0.01$. 


\section{ONLINE APPENDIX}


A Additional Analyses 


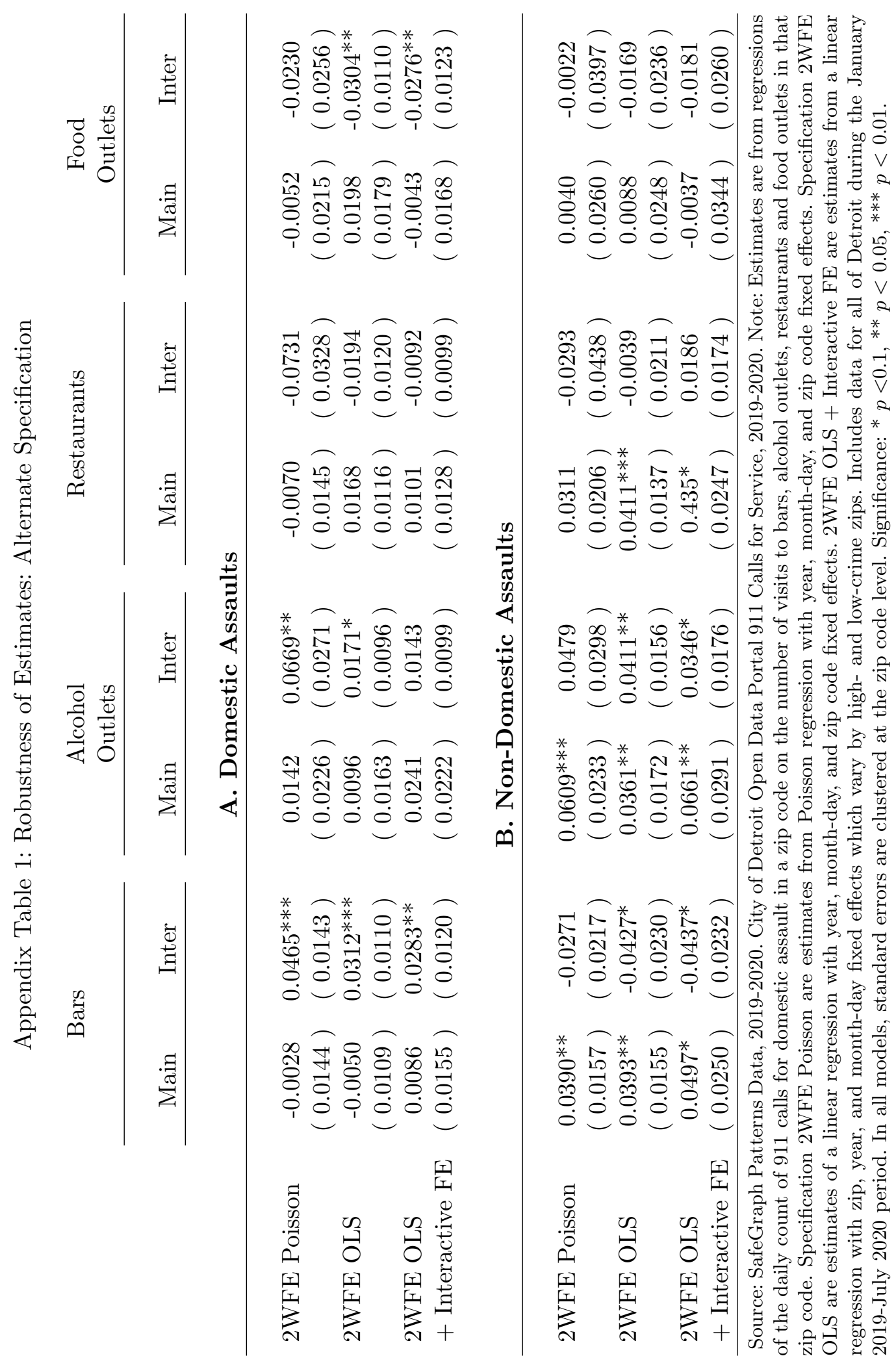

